\title{
Free Seed Aid Distribution in South Sudan and its Effect on Local Varieties of Sorghum and Maize
}

\author{
Author: Samuel D. Maguet \\ Concentration Mentor: Dr. Louise Sperling \\ Concentration Advisor: Prof. Patricia B. Mutch \\ International Development Program \\ Andrews University, Berrien Spering, Michigan USA
}

\begin{abstract}
The staple food crops grown in South Sudan are sorghum and maize constituting $80 \%$ and $15 \%$ of production respectively. The purpose of this study is to explore effects of free sorghum and maize seed distributions to farmers in Jonglei state and to assess how these distributions affect farmer seed use of local varieties of these two crops.

The guiding question: does free seed aid distribution have an effect on farmers' use of local varieties of sorghum and maize? The sub-questions are: do combination of local and modern (formal) seed makes farmers dependent on seed aid distribution? How do modern sorghum/maize varieties perform (in terms of yield) compared to local sorghum and maize varieties?

In this study, the local seed varieties in question focus exclusively on sorghum and maize. A positive effect is defined as follows: despite free seed aid distribution to farmers, local seed varieties are still being grown by farmers. A negative effect is seen as the inverse: free seed aid distribution limits the use of local seed varieties. The project data was collected from four selected Counties in South Sudan: i.e. Bor, Twic East, Pochalla and Pibor. (A county is an administrative area governed by a commissioner). The project was delimited to two Payams (Payam is a sub-county, an administrative area governed by a civil administrator) per County. The sample size of those interviewed included 152 individual respondents and 10 focus groups. This sample included: farmers, focus groups (all were women), and officers working for various organizations i.e. government, non-governmental organizations and private sector. Findings indicate that local varieties have advantages over formal varieties as they are adapted to the environment and often have good resistance to flood dry spells, pest and diseases. Local varieties are also said by farmers, to be palatable. Grain from local varieties is also transformed into local brew which is consumed during special events like marriage or even at leisure. This is commonly practiced in Pochalla County. Although farmers liked local varieties, there are varieties they couldn't do without e.g. athil/beer in the case of Bor and Twic East. Gannue and zichinolo varieties are liked most in Pochalla and Pibor respectively. It is apparent that free seed aid distribution does not affect local varieties use in Bor, Twic East and Pibor. However, the inverse is true for Pochalla because farmers prefer either local or formal varieties. This indicates that, continued distribution of free seed aid by Agencies/NGOs in the County could result in likelihood of local varieties extinct in the County. It was also evident that some varieties which used to be in circulation before the war are now not in circulation. I am of the opinion that Donors, NGOs and UN Agencies try other approaches which can support local varieties of sorghum and maize. For instance, local seed fairs through voucher system targeting local varieties was tried by few NGOs and Agencies and appeared to be working pretty well. In this way, intervention accountability would be to the people (beneficiaries).
\end{abstract}

Keywords: Free seed aid distribution effect, local/formal varieties, sorghum/maize performance

\section{Purpose, Rationale, and Scope of the Study}

\section{Introduction}

In South Sudan, sorghum constitutes $80 \%$ while maize makes $15 \%$ of production of the staple food consumed (Steve et al, 2002). Given such high percentage, sorghum is the major staple food crop in the country followed by maize. During the civil war (1983-2004) in the Country, formal production institutions were destroyed. Despite this fact, farming institutions were still active in that farmers were able to support themselves till the signing of Comprehensive Peace Agreement (CPA) in January $9^{\text {th }}$ 2005. Reliance on seed/food aid was very minimal (Norwegian People's Aid food aid records 2005-2010). Influx of seed aid especially for the staple food crops sorghum and maize started immediately with the signing of the CPA (Norwegian People's Aid). Aid agencies and non-governmental organizations believed that provision of seed (sorghum and maize) is a means of restoring disabled farming institutions. It is not clear whether or not seed aid provision is restoring agricultural institutions. 
The purpose of this study is to explore effects of free sorghum and maize seed distributions to farmers in Jonglei state and how this aid affects farmer use of local varieties of these two crops. Remington et al. (2002) asserts that, "formal seed system restricts farmer seed system and hence encourages dependency on them" (pg.7). Formal seed are always regarded as of high quality.

The study took approximately 15 months. Data collection took about nine months. Data analysis and reporting writing took six months. Participants were educated on the scope of the proposal and consent paper signing. A trial of questionnaires (a pre-test) with few farmers was carried out to see if they (farmers) could understand and answer the questions anticipated.

\section{Guiding Questions}

The central question is based on the effect of free seed aid distributions on local varieties. It goes as follow: Does free seed aid distribution have an effect on farmers' use of local varieties of sorghum and maize?

The sub-questions are two and these are: do combination of local and formal varieties makes farmers dependent on seed aid distribution? How do modern sorghum/maize varieties perform (in terms of yield) compared to local sorghum and maize varieties?

\section{Definition of Terms}

Local varieties mean informal varieties of sorghum and maize grown traditionally by farmers for at least a decade. Seed aid means either formal or informal varieties of sorghum and maize distributed to farmers through relief seed aid. Effect of the free seed aid distribution means both positive (despite free seed distribution to farmers, local varieties are still being used by farmers) or negative (free seed aid distribution limits the use of local varieties). Formal varieties are varieties mostly bought from seed companies by agencies and nongovernmental organizations. The following table contains some of local and formal varieties of sorghum and maize.

Table 1: Local and Formal Varieties of Sorghum and Maize used in Bor and Twic East County

\begin{tabular}{|l|l|l|l|}
\hline List of local varieties (sorghum) & List of local varieties (maize) & List of formal varieties (sorghum) & List of formal varieties (maize) \\
\hline Dhuet (brown) & Thoo-yol (yellow) & Serena & Katumani \\
\hline Nuer-baai/tung-gong (brown) & Acok-yaar (yellow) & Ketmani & TZB \\
\hline Beer/Athil (light yellowish) & Yar (white) & Sekedo & TZSR \\
\hline $\begin{array}{l}\text { Akur-acoot (white with black } \\
\text { spots) }\end{array}$ & & Seredo & Western yellow \\
\hline Lith (redish) & & Merese & TZBCOP.4 \\
\hline Kec (yellowish) & & Diri & AFRO 329 \\
\hline Jak (white with black spots) & & Wad el hamed & Longi-1,2,3,4,8 and 10 \\
\hline Agaany (light yellow) & & & Mugtanma-45 \\
\hline Thiep (white) & & & \\
\hline Ayen-cek (yellow) &
\end{tabular}

Source: NPA Farmer Training Center records (Bor/Twic East 2005-2010)

Note: not all varieties used in the research areas are listed in the table above. Only varieties used in Bor and Twic East County were listed for local varieties of sorghum and maize. For the local varieties of sorghum and maize, description of the variety colour is also given.

\section{Limitations of the Study}

This study is neither exhaustive nor comprehensive. More studies could still be carried out to determine the effect of free seed aid distribution on local varieties of sorghum and maize seed and its relation in food security.

\section{The Importance of the Study}

The importance of this research is to extend knowledge on the effect of free seed aid distribution on farmers' use of local varieties of sorghum and maize in South Sudan and what it means in the food security direction of the Country. Also, it will help in re-shaping strategic thinking on how to tackle issues of food insecurity.

\section{Review Of Related Literature}

Secondary data from the work of research institutions, agencies and Non-Governmental Organizations (NGOs) on seed delivery indicates about 2000mt of formal sorghum and 970mt of formal maize seed were delivered to Jonglei state during the period from 2004-2011 (Sperling, L., et al 2010). Seed and tools programmes have been widely implemented throughout South Sudan as a way of increasing the population's 
food security (McGuire, 2007) as quoted in (Jones et al., 2002). Lack of food is always connoted to result in a lack of seed (Ibid.) Free seed aid delivery takes a different perception where seed quality comes in handy. When an unexpected natural phenomenon strikes e.g. flood or drought and little is harvested, farmers can still save seed from the little they harvested for the next season's planting. In spite of this fact, more free seed is still distributed given the assumption that farmers have no seed due to the disaster. Yet there is no effective demand for seed beyond that generated by relief agencies themselves, (Jones et al. 2002).

Years back before and after 1956 civil war there were a series of natural phenomena i.e. flood and drought. Yet farmers were able to support themselves seed-wise for cultivation. (This information was obtained through my interaction with elderly in the communities), During the second civil war which started in 1983, there were as well a series of other natural phenomena including flood, drought, and crop failure as well as livestock diseases outbreak. But still farming communities of South Sudan were able to plant own saved seed. Lautze (2003) noted that field research in targeted areas for relief seed found that farmer seed systems continue to meet the crop and varietal needs of farmers even following 1998 famine. When the Comprehensive Peace Agreement (CPA) was signed on January $9^{\text {th }} 2005$, free relief seed aid became increasing more important in some parts of the Country notably, Jonglei state where internal conflicts among pastoral and peasant communities continue to rage. Currently, free seed aid to the Country is estimated to about 2000 tonnes per annum, (Sperling et al. 2010). In Jonglei state, where this research is carried out, the annual seed aid i.e. sorghum and maize is estimated at 470.5mt and 388.5mt respectively, (FAO, 2006-2011; NPA, 2005-2010; CARE Int.,2005-2007; LWF, 2007-2010; and ADRA, 2007-2010 records).

I am not sure whether or not these perceived high quality sorghum and maize seed varieties perform to the expectations! In 2009, imported sorghum variety (sekedo) distributed in Twic East County grew vegetatively to a height of about more than 4 meters and took a period of six months but never boot (a stage before flowering in sorghum commonly known as boot leaf stage) (NPA FTC records 2009). Although some imported sorghum varieties could perform well in the first cropping, they could not yield in the second cropping e.g. Serena sorghum variety. (NPA FTCs record 2007). This is true for the hybrid maize seed produced expensively and fail to perform in the second cropping when seed from the first cropping is grown in the second cropping season.

Remington et al (2002) noted, formal seed system restricts farmer seed system and hence encourage dependency on them and yet farmers don't afford them since they are produced expensively for instance hybrid seed. Resource poor farmers are challenged by this system.

Traditionally and before the war, (1956 and 1983) farmers in South Sudan used to have enough sorghum seed to plant and get good harvest (Information gathered from elderly in the search areas). This fact turned out the opposite during and after the war because of influx of aid agencies and non-governmental organizations. Free seed aid distribution for sorghum and maize remained important as a result of quality issue which is valued by donors and agencies. Chemonics [(1996) as quoted in Remington et al 2002)], Defined seed quality as certified seed by formal sector. However, informal seed sector remains the major supplier of seed of improved and local varieties of many crops grown by small-scale farmers (Thijssen, et al. 2008).

\section{Type of Design}

\section{Methodology}

The aim of this study is to investigate the effect of free seed aid distribution on local seed varieties. Local seed varieties are defined as sorghum and maize. The effect is either positive (despite free seed aid distribution to farmers, local varieties are still being grown by farmers) or negative (free seed aid distribution limits the use of local varieties) on local varieties. The study focus is the point where free seed aid distribution and local varieties affects the latter.

\section{Selection and Description of the site and the Participants Site and participants}

The project data was collected from four selected sites which are Bor, Twic East, Pochalla, and Pibor Counties (a county is an administrative area governed by a commissioner). From the counties, the project was delimited to two Payams (Payam is a sub-county, an administrative area governed by a civil administrator) per county. The selection was done based on the two crops under investigation. Pochalla and Pibor Counties are known for maize growing. Bor and Twic East Counties are known for their sorghum growing. Besides that, these Counties are operational areas of NPA thus allowing for easy accessibility.

There were samples of 10 focus groups, 142 famers and 10 agriculture officers working for the government and/or agencies and international non-governmental organizations. The respondents were derived from two groups. First group were farmers who were interviewed from their own farms. The second group was those working for government and international non-governmental organizations and or agencies. The project assistants conducted interviews with the first group i.e. farmers since most of them don't read and write. The second groups i.e. those working for government and non-governmental organizations and agencies filled in the 
forms by themselves. The main investigator led the second group. The participants in the focus group signed or mark their names on the informed consent form. The consent forms were read to them.

\section{Questionnaires}

Each of the 10 agriculture officers working for government and/or agencies and international nongovernmental organizations individually filled in the questionnaires (Appendix B) by themselves. The same questionnaire (Appendix B) were used by farmers and administered by the research assistants. Focus groups with guided discussions had set of questions in a separate form (Appendix C). The consent forms were signed by each participant.

All respondents each signed the consent document before providing information required of them. Prior to signing of the consent paper, the respondents were educated on the process of the research. The forms which are filled were collected and handed over to the main investigator for safety and data analysis.

\section{Ethical Considerations}

The principal investigator and the assistant investigators work for humanitarian organization and do not have any relationship with the people sampled as respondents. The participants were provided with information about the purpose of the study. Participants' privacy and anonymity of the information they provided was protected. Each participant signed a consent form (Appendix A) attached to the questionnaire. The research assistants will receive a copy of the research study at conclusion.

\section{Data Collection Strategies}

Data collection took nine months contrary to time estimated previously. Before commencement of data collection, participants were educated on the scope of the project followed by signing of the consent form by each respondent. A total of 162 questionnaires were administered to farmers, focus groups and project officers working for government, non-governmental organizations and agencies. Data collection started in July 2012 and ended in April 2013. Data analysis and report writing which commenced in June 2013 and ended in November same year, it took six months.

\section{Data Analysis Strategies}

Participants' responses were tabulated and statistical comparison using t-test for independents variables which were made on the responses to the questionnaires. ANOVA was used for quantitative data analysis.

\section{Methods of Achieving Validity}

A trial of the questionnaires with a few farmers was conducted to see if they understand and can answer the questions anticipated.

\section{Description of Findings}

\section{Findings}

\section{Socio-economic features of the sample farmers}

A sample size of 152 respondents used individual questionnaires and a sample size of 10 focus groups used guided questionnaires. Table No. 1 below shows socio-economic features of the sample farmers who used individual questionnaires.

Table 2: Socio-Economic Profile of the Sample Farmers

\begin{tabular}{|c|c|c|c|c|c|c|c|c|c|c|}
\hline \multirow[b]{2}{*}{ County } & \multirow[b]{2}{*}{$\mathbf{N}$} & \multicolumn{3}{|c|}{ Household } & \multicolumn{2}{|c|}{ Gender } & \multirow{2}{*}{$\begin{array}{l}\text { Ave } \\
\text { Age }\end{array}$} & \multicolumn{3}{|c|}{ Acreage } \\
\hline & & Residents & IDPs & Refugees & Female & Male & & 1 & 2 & 3 \\
\hline Bor & 39 & 32 & 7 & 0 & 9 & 30 & 48 & 16 & 10 & 13 \\
\hline Twic East & 40 & 40 & 0 & 0 & 26 & 14 & 43 & 24 & 8 & 8 \\
\hline Pochalla & 33 & 23 & 0 & 10 & 13 & 20 & 36 & 18 & 2 & 13 \\
\hline Pibor & 40 & 33 & 7 & 0 & 10 & 30 & 41 & 19 & 7 & 14 \\
\hline Total & 152 & 128 & 14 & 10 & 58 & 94 & 42 & 77 & 27 & 48 \\
\hline
\end{tabular}

For the individual questionnaires, 128 were residents, 14 internally displaced persons (IDPs) and 10 refugees. There were more men who answered questions then women in individual questionnaires. The average age of those interviewed was 42 years both for individual questionnaire and focus group discussion. On average, a farmer cultivates 1 feddan (a feddan is equivalent to 4200 Square meters).

The sampled10 focus group discussions were mainly women groups. This shows more women than men participated in this research work. Each group comprises about 15 women on average. This made the number of women more than that of men. The groups were a mixed up of residents, internally displaced persons 
and refugees. Like the case of individual questionnaires, the sampled 10 groups under focus group discussion cultivate on average 1 feddan per season.

Farmers said they could get up to $450 \mathrm{~kg}$ of sorghum and $250 \mathrm{~kg}$ of maize per feddan per season. Farmers were skeptical of seed they get from NGOs and UN agencies. The reason given for the skepticism was that they (farmers) are not familiar with seed. However, some of the respondents (farmers) acknowledged the fact that they also do try formal varieties to compare them with varieties they have locally and get the best out. Given this finding, it was also found out that some varieties which used to exist in the past are now not in circulation! These include: atuong, thiang-yol, thiep, bicat, and mading for sorghum. Maize varieties that are currently not in circulation are: acok-yaar, thoo-yol and mabior. These varieties are the ones used in Bor and Twic East. The same notion could not be established in Pochalla and Pibor.

Some of the farmers expressed concern that formal varieties they get from NGOs and agencies sometimes fail them (not yielding to the expectation). The following point was discussed extensively during one of the focus group discussion, "Wad-hamed, a formal sorghum variety does very well compared to other local varieties!" said one of the group members. However, another group member responded differently! She said, "With first impression, she kept seed for this variety for the second and third seasons. Yields were gradually declining in the second and third seasons." Therefore, for those farmers who might have succeeded in planting and harvesting formal varieties, the yield actually reduce gradually and the farmers may need more seed for planting next season. This fact, to majority of farmers is a waste of energy and time.

Primary sources of seed: current strategies, 2012.

The findings indicate that primary source of planting material i.e. maize and sorghum is own saved. These findings are presented in three tables from 3a to 3c. Table 3a shows percent of each source of seed from each County. Tables $3 \mathrm{~b}$ and $3 \mathrm{c}$ incorporate crops percentages. The table $3 \mathrm{a}$ shows percent source of seed per County. Total each source is the average of the four Counties which provided the following: $78.2 \%$ own saved; 12.6\% external agencies; $5.7 \%$ local market and 3.6\% kin. Pibor had lower percentage as far as own stock sources of seed are concerned. The reason could be due to accessibility of formal seed from aid agencies and non-governmental organizations. This is denoted by $46.2 \%$ of external agencies and non-governmental organizations as sources of seed. It was only Pibor and Pochalla where kinship had $12.4 \%$ and $1.8 \%$ respectively. Responses from respondents showed that they (farmers) still get seed from relatives and friends. Local market sources of seed vary as well with Bor respondents showing 2.6\%, Twic East 2.5\% and Pochalla $17.5 \%$. Pochalla had the highest percentage of farmers who source seed from the local market. Since this result showed no market source of seed from Pibor, there could be no local market system for seed in the County. Pochalla borders Ethiopia and could be the reason it has the highest percentage of market source of seed.

Table 3a: Farmers' Primary Sources of Seed, (current strategies 2012)

\begin{tabular}{|l|l|l|l|l|l|l|}
\hline \multirow{2}{*}{ County } & \multirow{5}{*}{$\mathrm{N}$} & \multicolumn{2}{|l|}{$\begin{array}{l}\text { Seed source } \\
\text { (\% of seed from each source) }\end{array}$} & $\begin{array}{l}\text { Total } \\
\text { Seed } \\
\text { source }\end{array}$ \\
\cline { 3 - 7 } & Own stocks & Kin & $\begin{array}{l}\text { External } \\
\text { agency }\end{array}$ & $\begin{array}{l}\text { Local } \\
\text { markets }\end{array}$ & \\
\hline Bor & 39 & 97.4 & 0 & 0 & 2.6 & 100.0 \\
\hline Pochalla & 33 & 76.6 & 1.8 & 4.1 & 17.5 & 100.0 \\
\hline Twic east & 40 & 97.5 & 0 & 0 & 2.5 & 100.0 \\
\hline Pibor & 40 & 41.4 & 12.4 & 46.2 & 0 & 100.0 \\
\hline Total & 152 & $\mathbf{7 8 . 2}$ & $\mathbf{3 . 6}$ & $\mathbf{1 2 . 6}$ & $\mathbf{5 . 7}$ & 100.0 \\
\hline
\end{tabular}

On the other hand; table $3 \mathrm{~b}$ shows average percentage for each crop type, as per this research, grown by farmers per area of research. Farmers from Pochalla and Pibor grow more maize than sorghum. The converse is true for Bor and Twic East.

Table 3b: Farmers' Primary Sources of Seed, (current strategies 2012)

\begin{tabular}{|c|c|c|c|c|c|c|c|c|}
\hline \multirow[b]{2}{*}{ County } & \multirow[b]{2}{*}{$\mathrm{N}$} & \multirow[b]{2}{*}{ Sorghum } & \multirow[b]{2}{*}{ Maize } & \multicolumn{4}{|c|}{$\begin{array}{l}\text { Seed source } \\
\text { (\% of seed from each source) }\end{array}$} & \multirow{2}{*}{$\begin{array}{l}\text { Total } \\
\text { Seed } \\
\text { source }\end{array}$} \\
\hline & & & & Own stocks & Kin & $\begin{array}{l}\text { External } \\
\text { agency }\end{array}$ & $\begin{array}{l}\text { Local } \\
\text { markets }\end{array}$ & \\
\hline Bor & 39 & 83.2 & 16.8 & 97.4 & 0 & 0 & 2.6 & 100.0 \\
\hline Pochalla & 33 & 5.9 & 94.1 & 76.6 & 1.8 & 4.1 & 17.5 & 100.0 \\
\hline Twic east & 40 & 97.0 & 3.0 & 97.5 & 0 & 0 & 2.5 & 100.0 \\
\hline Pibor & 40 & 32.4 & 67.6 & 41.4 & 12.4 & 46.2 & 0 & 100.0 \\
\hline
\end{tabular}


Free Seed Aid Distribution in South Sudan and its Effect on Local Varieties of Sorghum...

\begin{tabular}{|l|l|l|l|l|l|l|l|l|}
\hline Total & 152 & 54.6 & 45.4 & $\mathbf{7 8 . 2}$ & $\mathbf{3 . 6}$ & $\mathbf{1 2 . 6}$ & $\mathbf{5 . 7}$ & 100.0 \\
\hline
\end{tabular}

Table $3 \mathrm{c}$ further divides the crops sources into percentage by taking the average. The growing trends with the figures indicate steady move from own stock seed source to local market and external agencies. This also indicates the importance of local market for seed sourcing. All mentioned sources of seed are important, to some degree, to farmers although not from all Counties! Pibor and Pochalla which have the highest percentage of maize appeared to have high percentage of seed source from both external agencies and own stock.

The implication is that, farmers might be using formal seed and keep them as own stock. The same (formal seed) might reach the local market system and taken for local varieties. This scenario is most apparent in Pibor and Pochalla County. The other two Counties have a different scenario since their only source of seed is own stock and local market.

Table 3c: Farmers' Primary Sources of Seed, (current strategies 2012)

\begin{tabular}{|c|c|c|c|c|c|c|c|}
\hline \multirow[b]{2}{*}{ County } & \multirow[b]{2}{*}{ Crop } & \multirow[b]{2}{*}{$\mathrm{N}$} & \multicolumn{4}{|c|}{$\begin{array}{l}\text { Seed source } \\
\text { (\% of seed from each source) }\end{array}$} & \multirow{2}{*}{$\begin{array}{l}\text { Total } \\
\text { Seed } \\
\text { source }\end{array}$} \\
\hline & & & $\begin{array}{l}\text { Own } \\
\text { stocks }\end{array}$ & Kin & $\begin{array}{l}\text { External } \\
\text { agency }\end{array}$ & Local markets & \\
\hline Bor & sorghum & & 90.6 & 0 & 0 & 9.4 & 100.0 \\
\hline \multirow{2}{*}{ Pochalla } & sorghum & & 28.9 & 23.5 & 24.3 & 23.3 & 100.0 \\
\hline & total & 33 & 50.9 & 13.5 & 14.8 & 20.8 & 100.0 \\
\hline Twic east & maize & & 49.7 & 0 & 0 & 50.3 & 100.0 \\
\hline \multirow{2}{*}{ Pibor } & sorghum & & 32.5 & 31.3 & 36.2 & 0 & 100.0 \\
\hline & total & 40 & 37.4 & 22.9 & 39.7 & $\mathbf{0}$ & 100.0 \\
\hline Total maize & & & 55.4 & 4.5 & 12.1 & 28.0 & 100.0 \\
\hline Total sorghum & & & 62.3 & 13.7 & 15.1 & 8.9 & 100.0 \\
\hline Total- across crops & & 152 & 58.9 & 9.1 & 13.6 & 18.4 & 100.0 \\
\hline
\end{tabular}

Historical sources of seed.

According to the findings of this research, the pre-war period of 1972-1982 farmers relied heavily on their own seed stock. Almost all respondents said they were using their own seed stock before the war. Post-war sources showed that majority of respondents still use their own seed stock. Unlike the pre-war period where $100 \%$ relied on their own saved seed, post-war period had $71.2 \%$ of respondents using their own seed, and those using seed from external agencies and other sources were $16.4 \%, 10.5 \%$ and $1.9 \%$ respectively. Table number No. 4 below shows the findings. In Bor County, own stock source led by $65.8 \%$ followed by local market sources with $28.9 \%$. External agencies and kin sources came in third and fourth place with $2.7 \%$ and $2.6 \%$ respectively. Sources in Pochalla County had own stock $93.9 \%$ followed by external agencies and local market with $3.1 \%$ and $3.0 \%$ respectively. Twic East County, own stock was $95.0 \%$ followed by external agencies and kin with $2.5 \%$ each. No local market seed sourcing in the County during the period. In Pibor, the major source of seed is external agencies with $57.5 \%$ followed by own stock $30.0 \%$. Local market and kin were third and fourth with $10.5 \%$ and $2.5 \%$ respectively.

Table 4: Farmers' Post-war Sources of Seed (2005-2011)

\begin{tabular}{|l|l|l|l|l|l|l|}
\hline \multirow{2}{*}{ County } & \multirow{2}{*}{$\begin{array}{l}\text { Seed source } \\
\text { \% of seed from each source) }\end{array}$} & Total \\
\cline { 3 - 8 } & $\mathrm{N}$ & Own stocks & Kin & $\begin{array}{l}\text { External } \\
\text { agency }\end{array}$ & $\begin{array}{l}\text { Local } \\
\text { markets }\end{array}$ \\
\hline Bor & & & 2.6 & 2.7 & 28.9 & 100.0 \\
\hline Pochalla & 39 & 65.8 & 0.0 & 3.1 & 3.0 & 100.0 \\
\hline Twic east & 33 & 93.9 & 2.5 & 2.5 & 0.0 & 100.0 \\
\hline Pibor & 40 & 95.0 & 2.5 & 57.5 & 10.0 & 100.0 \\
\hline
\end{tabular}


Free Seed Aid Distribution in South Sudan and its Effect on Local Varieties of Sorghum...

\begin{tabular}{|l|l|l|l|l|l|l|}
\hline Total & 152 & 71.2 & 1.9 & 16.4 & 10.5 & 100.0 \\
\hline
\end{tabular}

Variety preference.

The findings show that most farmers prefer local varieties compared to the formal varieties. Table No. 5 below lists varieties in the four research areas. Respondents from Bor and Twic East County are from the same ethnic group and use the same language. They have the same names for varieties they use as well. Formal varieties are nicknamed by the locals from Pochalla and Pibor County. However, in this research, I maintained the original names for varieties e.g. serena and longi4 and disregard the nicknames to avoid confusion. In the column of varieties preference, I have not made any distinction between crop type varieties as it can easily be referred to in the other columns. It should be noted that, all local varieties are preferred. The most preferred varieties are in the last two columns.

Table 5: List of Varieties Found Among Sampled Farmers in the four Counties

\begin{tabular}{|c|c|c|c|c|c|c|}
\hline \multirow[t]{2}{*}{ County } & \multicolumn{2}{|c|}{ Sorghum } & \multicolumn{2}{|c|}{ maize } & \multicolumn{2}{|c|}{ Varieties preferred } \\
\hline & Local & Formal & Local & Formal & Local & Formal \\
\hline \multirow[t]{17}{*}{ Bor/T. East } & Athil/beer & Serena & Tho-yol & Longi $1,2 / 3$ & Athil/beer & Longi 4,5 \\
\hline & Akur-acot & Wed-hamed & Acok-yaar & DHO3 & Akur-acot & \\
\hline & Agaany & Sekedo & $\mathrm{Kec}$ & DHO4 & Lith & \\
\hline & Nuer-baai & nyorongo & Mataba & H515 & & \\
\hline & Kec-cek & & Mabior & H624 & & \\
\hline & Luel & & Makaraka & Yellow corn & & \\
\hline & Dhuet & & Kompilany & & & \\
\hline & Tung-gong & & & & & \\
\hline & Lith & & & & & \\
\hline & Thiang-yol & & & & & \\
\hline & cala & & & & & \\
\hline & Ayen-cek & & & & & \\
\hline & Thiep & & & & & \\
\hline & Thiep & & & & & \\
\hline & Agon-kou & & & & & \\
\hline & Jak & & & & & \\
\hline & Alok-pei & & & & & \\
\hline \multirow[t]{6}{*}{ Pochalla } & Gannge & Serena & Otwiele & Longi $1,2 / 3$ & Orobollo & Longi 4,5 \\
\hline & Wattee & Wed-hamed & Galle & DHO3 & Gannue & Yeollow corn \\
\hline & Abuoi & Sekedo & Otulle & DHO4 & Otwiele & \\
\hline & & Gaug & & H515 & Galle & \\
\hline & & & & H624 & & \\
\hline & orobollo & nyorongo & & Yellow corn & & \\
\hline \multirow[t]{6}{*}{ Pibor } & Kuturbong & Atila & Mabior & Longi $1,2 / 3$ & Nyoro & Longi 5 \\
\hline & Ngalorja & Canda & & DHO3 & Mabior & Yellow corn \\
\hline & & Kurkujet & & DHO4 & Zichinolo & \\
\hline & & Batilongony & & H515 & & \\
\hline & Bilnyang & & & H624 & & \\
\hline & & & & Yellow corn & & \\
\hline
\end{tabular}

The table 6 below shows percentage of respondents who prefer either variety per County. Local varieties are preferred by majority of farmers. Only $30.8 \%$ of the respondents would prefer formal varieties.

Table 6: Variety Preference per County

\begin{tabular}{|l|l|l|l|l|}
\hline County & $\mathbf{N}$ & \% local varieties & \% formal varieties & Total \\
\hline Bor & 39 & 74.3 & 25.7 & 100 \\
\hline Twic East & 40 & 95.1 & 4.9 & 100 \\
\hline Pochalla & 33 & 49.3 & 50.7 & 100 \\
\hline Pibor & 40 & 61.7 & 38.3 & 100 \\
\hline Total & $\mathbf{1 5 2}$ & $\mathbf{6 9 . 2}$ & $\mathbf{3 0 . 8}$ & $\mathbf{1 0 0}$ \\
\hline
\end{tabular}

The respondents gave several reasons as to why they prefer local varieties as explained in figure 1 below. It appeared that respondents from Pochalla and Pibor do not mind which variety is available! Although they prefer local varieties, they also want to try formal varieties to compare with the local varieties. 


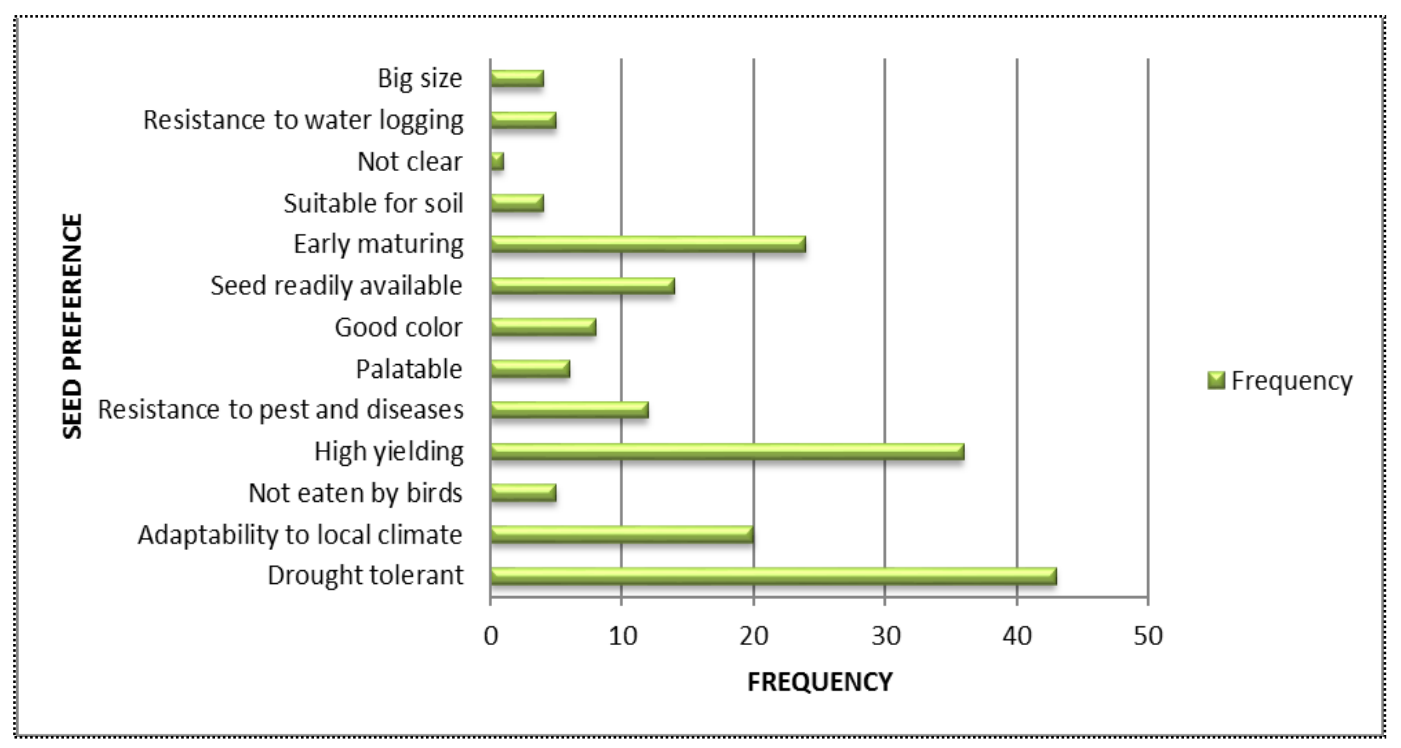

Figure 1: Reason for Variety Preference

\section{Discussion of the Findings}

Household status indicates more residents participated in the research compared to internally displaced persons (IDPs) and refugees. Internally displace persons are those, who during the war were displaced from their original domicile to the current domicile where they were interviewed. Refugees are Ethiopian by nationality and from Anuak ethnic group. They have been to Pochalla since the fall of Mingisto regime in early 1990. The significance of household status is to show validity of the findings given the profile of sorghum and maize varieties grown over a period of time. Since we have more residents than IDPs and refugees, I assume that views or answers they provide are true.

Although it appears as if there were more men than women in table 2 above, the figure shows those who answered questions for individual questionnaires. When it comes to focus group discussion, which were only women groups, the inverse is true. The importance of gender in this study is the role played by each sex. Women are known of their ability to storing seed safe in traditional granaries or where seed could be reached by smoke (fire place) as a repellent to insect pests and diseases. Women also do most of the work in smallholder farmer setup.

The active age in farming, especially here in South Sudan, is between 30-50 years. The average age of 42 represents for both pre-war as well as post-war periods. The maximum age of those interviewed was 89 and minimum 25. Therefore, the knowledge on varieties grown is well spread across generations.

The unit of measure here in South Sudan is feddan (an equivalent of 4200 meter square). On average, respondent cultivates 1 feddan per season. The area cultivated each season does not necessarily entails sorghum or maize varieties in the same acreage, there could be other crops e.g. cassava, millet and beans.

In general, findings indicate that the main primary source of seed is own stock followed by external agencies, local market and then kin. This finding does not concur with the finding noted by Jones et al., (2002) "there is no effective demand for seed beyond that generated by the relief agencies themselves." Seed source from external agencies could be second alternative to locally sourced seed. Looking at the three periods, prewar, post-war and the current strategies; there is a clear distinction between the periods. During the pre-war farmers were relying on own seed stock. Although farmers still rely on own stock during the post-war period, this was not $100.0 \%$. About $28.85 \%$ of respondents had other sources of seed other than own stock. Only $71.2 \%$ of the respondents used own stock during the period.

This concurs with what was exerted by Remington (2002), "even though formal seed system restricts farmer seed system and encourage dependency, farmers actually use their own seed." Perhaps farmers just take seed for the sake of having them and may use them differently but not as planting material! Only some few farmers who are at the same time desperate of having seed for planting during a specific planting season.

Current strategies (table 3a 2012) showed an increase of 7.0\% in own seed stock sourcing making it $78.2 \%$ on average. Given these findings, it could be deduced that there could be reduced seed delivery during (2005-2011) by agencies and non-governmental organizations with $3.8 \%$ in 2012. There is also decline in local market source of seed from $10.5 \%$ during (2005-2011) to 5.7\% in 2012. In this case farmers relied heavily on their own stock. This finding is also noted by Thijussen, et al., (2008) and I quote, "informal (local) seed sector 
remains the major supplier of seed of improved and local varieties of many crops grown by small-scale farmers." However, this trend could also be due to reduced free seed aid distribution by agencies and nongovernmental organizations and thus farmers thought of reverting to their normal way of seed sourcing. Since famers in Pochalla and Pibor prefer both local and formal varieties of the seed according to the research findings, it emphasized on the finding by Thijussen as indicated in the same paragraph.

There are several varieties used by farmers in the areas of research. Of these varieties, some of them are listed in table No. 5 above. Although local varieties are listed as preferred by farmers, there are those most preferred. Several reasons were given by the respondents as to why they prefer local varieties as shown in figure No 1 on the findings above. Here in South Sudan, hunger gap is very significant especially with the rural people. The period between June and July each season is very critical and could be the reason why farmers prefer early maturing varieties so that gaps are closed during critical months. Farmers experienced or been experiencing natural phenomena like flood, draught, pests and diseases some of which could be devastating. Some local varieties could have developed resistance to some of these occurrences over a period of time. Farmers then want to use what they think they could get something out of (local varieties). The fact that some farmers like formal varieties is may be to try them and compare them with local varieties they already have. However, most farmers trusted their own saved seed and are skeptical of formal seed they get from NGOs and agencies. This concurs with the finding noted by Lutze (2003) and I quote "farmer seed systems continue to meet crop and varietal needs of famers even following 1998 famine". When farmers plant formal varieties which are not well-known to them, they (farmers) experience both advantages and disadvantages.

As mentioned in the findings, there are some varieties which are currently not in circulation. There are three possible reasons that could have led to that situation. i) the protracted civil war in South Sudan could have led to disappearance of these varieties. ii) free seed aid distribution by agencies and non-governmental organizations. iii) since some of the varieties were susceptible to pests and diseases could be another reason that led to their disappearance.

\section{Summary}

Despite continued free seed aid distribution to famers in South Sudan, they (farmers) still use local varieties of seed as planting material each planting season. This is shown by high percentage of famers who prefer local seed varieties to formal varieties. However, formal varieties are in use as well. $30.8 \%$ of the respondents prefer formal varieties. In this regard, seed sources and variety preferences are significantly different. This explains that irrespective of farmers own seed stock the varieties kept could be formal varieties!

In regard to the research question, whether or not free seed aid distribution have an effect on farmers' use of local varieties of sorghum and maize. According to the findings, it appears free seed aid distribution have no effect on farmers' use of local varieties. Farmers still use their local varieties of sorghum and maize. However, some local varieties which were in circulation before the war are currently not in circulation. This finding shows, although farmers still use their local varieties there is likelihood of more varieties disappearing in future should the trend of free seed aid distribution continue.

The first sub-question asks if combination of local and formal seed makes farmers dependent on seed aid distribution. Finding indicates that combining both local and formal varieties could lead to dependency on seed aid as it came out from findings in Pochalla and Pibor.

The second sub-question of the research asks whether sorghum and maize varieties perform (in terms of yield) compared to local sorghum and maize varieties. Local varieties perform better than formal varieties. Respondents gave an instance when formal varieties could perform much better in the first season and later performance goes down.

In general, I think it is critically important to consider farmers preferences and build on what they have locally. As mentioned earlier in the text, farmers use and prefer their local varieties because they have trust on the varieties since they are high yielding and resistance to natural phenomena such as flood, drought, pests and diseases. There are approaches that could support farmers' view. For instance, seed fairs through voucher system in a disaster and post-conflict situations like the example of South Sudan, could help support local seed varieties and thus encouraging farmer seed system. New technologies could as well be developed from local varieties. As asserted by (Jones, R., et al 2002), "farmers have well developed a resilient seed systems and exhibit a strong preference for locally adapted sorghum varieties." Farmers in most cases would want to experiment new technologies and compare them with what exists locally in the process, there is division of labour and reduced acreage. 


\section{References}

[1]. Almekinders, C., et al (2000). Local Seed Systems and their Importance for an Improved Seed Supply in Developing Countries. Euphytica 78:207-216.

[2]. Adventist Development and Relief Agency, South Sudand. (2011). Seed Delivery Records, 2007-2010. Bor, Jonglei State, South Sudan.

[3]. Cooperation for Assistance and Relief Everywhere, South Sudan. (2007) Seed Delivery Records 2005-2007. Bor, Jonglei State, South Sudan

[4]. Food and Agriculture Organization, South Sudan. (2012). Seed Delivery Records 2006-2011. Bor, Jonglei, South Sudan FAO, Seed Delivery Records 2006-2011

[5]. Jones, R., et al (2002). Disasters, the Need to Look Beyond the Production and Provision of Relief Seed. Experiences from Southern Sudan. Published by Blackwell Publishing Oxford Ox4 1JF, UK and Malden, MA 02148, USA

[6]. Lautze, S., \& Sites, E. (2003). More than Seeds and Tools. An overview of OFDA Livelihood Interventions. Feinstein International Famine Centre Tufts University. Retrieved on 22/08/2009. http://www.plantmethods.com/content/.../abstract.

[7]. Lutheran World Federation, South Sudan. (2011) Seed Delivery Records 2007-2010. Bor, Jonglei State, South Sudan.

[8]. McGuire, S., J. (2007). Security Access to Seed. Social Relations and Sorghum Seed Exchange in Eastern Ehiopia. School of Development Studies, University of East Anglia, Norwich NR 47TJ, UK. Retrieved on 23/05/2009 from http://www.allacademic.com/meta/p73044_index.html

[9]. Pingali, P., alinovi, L. \& Sutton, J. (2005). Food Security in Complex emergencies: enhancing food system resilience. Disasters, Volume 29, June 2005. Retrieved on $20^{\text {th }}$ May 2010 from http://www.sfc.ucdavis.edu/farmers_market/management/chp1. pdf

[10]. Nathaniel, N., et al (2000). Seed Fairs. The Case of Marambo Village, Nachingwea District, Tanzania. Implications of Local Seed Supply and Variety Development. Research and Extension Network Paper. No.101, AgREN, Overseas, Lonod.

[11]. Norwegian People's Aid, South Sudan. (2012) Seed Delivery Records 2005-2010. Bor, Jonglei State, South Sudan.

[12]. Ola, T., W. (2009). Assessment of Agriculture Inputs Distribution Impact on Seed System Secutrity and Inputs Markets in Jonglei State, South Sudan. Report.

[13]. Sperling, L., et al (2010). Seed System Security Assessment. Southern Sudan. Jointly carried out by International Center for Tropical Africa (CIAT), Food and Agriculture Organization (FAO), Government of Southern Sudan (GoSS), and International Nongovernmental Organizations (e.g. NPA, CRS, ADRA, ACTED). Sponsored by EU and USAID.

[14]. Sperling, L., \& Cooper, H.D (2003). Understanding Seed Systems and Seed Security in Improving the Effectiveness and Sustainability of Seed Relief. Proceedings of a Stakeholder's Workshop. Food and Agriculture Organization, Rome

[15]. Steve, A., et al (2002). Disaster. International Research Institute for the Semi-Arid Tropical. Volum 26, November, 4 December PP.356-367 (12). Black well Publishing. IRCISAT.

[16]. Remington, T., J. Maroko, S. Walsh, P. Omanga and E. Charles (2002) Getting off the seed and

[17]. tools treadmill with CRS seed vouchers and fairs. Disaster. The Journal of Disaster Studies, Policy and Management 26(4): 302-315.

[18]. Thijssen, M.H. Bishaw, A. Beshir and W.S. de Boef (2008) Eds. Farmers, Seed and Varieties: Supporting Informal Seed Supply in Ethiopia. Wageningen, Wageningen International. 348p.

\section{APPENDIX A:}

\section{Informed Consent Paper}

\section{Informed Consent Paper}

\section{Purpose of the study}

The aim of this study is to investigate the effect of free seed aid distribution on local seed varieties of sorghum and maize.

\section{Inclusion criteria}

In order to participate in this research, I must be an adult over the age of 20 and of sound mind, and must have practiced farming over the last five years or worked for government or international non-governmental organization for at least five years.

\section{Benefits/Results}

I understand I may not receive any direct benefits from participating in this study and accept I will receive no recommendation for my participation. I understand the results may assist the researcher provide insight on seed system in light on effect of free seed aid distribution on local seed varieties.

\section{Risks and Confidentiality}

I have been informed there is minimal risk to my involvement in this study and this will be minimized by confidential handling of any interview information, and I am aware the information I will provide will be for the research purpose and that my identity in the final document will be given with my consent.

\section{Voluntary Participation}

I understand my participation in this research is voluntary and I may discontinue my participation in this research at any time without penalty or prejudice. 
I agree to participate in this research which I understand will be submitted in partial fulfillment of the Master of Science in Administration Degree of Andrews University.

Participant's name:

Investigator's signature:

Signature:

Date:

\section{APPENDIX B:}

\section{Individual Questionnaire}

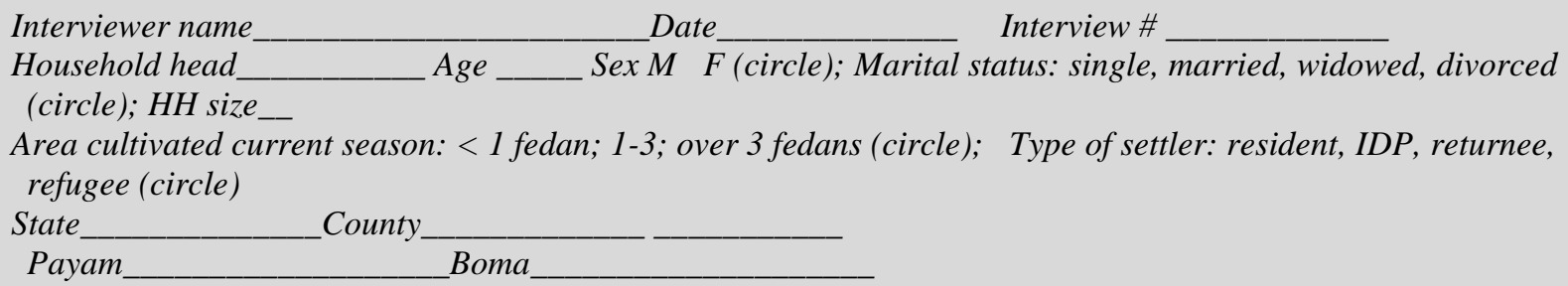

Part A. Type of crops and their source of seed

1. Sorghum and maize are important crops grown here. Indicate if you grow these crops, and if, so, for how long:

\begin{tabular}{|l|l|l|l|}
\hline Crop & $\begin{array}{l}\text { How many seasons } \\
\text { have you ever grown } \\
\text { this crop? Y/N }\end{array}$ & $\begin{array}{l}\text { Did you grow this crop the } \\
\text { most current season? } \\
\text { Y/N }\end{array}$ & If you stopped growing this crop, explain why. \\
\hline Sorghum & & & \\
\hline Maize & & & \\
\hline
\end{tabular}

2. For crops you continue to grow above, from where did you get seed this recent season?

List the sources in order of importance: $1=$ most important; $2=$ second source $3=$ third source $4=$ fourth source

\begin{tabular}{|l|l|l|l|l|l|}
\hline \multirow{2}{*}{ Crop } & \multicolumn{5}{|c|}{ Sources for seed } \\
\cline { 2 - 6 } & Own saved & Local market & kin & & \\
\hline Sorghum & & & & & \\
\hline Maize & & & & & \\
\hline
\end{tabular}

3. Before the war (from 1972-1982), what were your sources of seed?

\begin{tabular}{|l|l|l|l|l|l|}
\hline \multirow{2}{*}{ Crop } & \multicolumn{5}{|c|}{ Sources for seed } \\
\cline { 2 - 6 } & Own saved & Local market & kin & & \\
\hline Sorghum & & & & & \\
\hline Maize & & & & & \\
\hline
\end{tabular}

If there is a change between Question 2 and 3 explain why:

Change for sorghum

source

Change for maize

source

4. From 2005-2011 what have been your major sources of seed (sorghum and maize)?

\begin{tabular}{|l|l|l|l|l|l|}
\hline Crop & \multicolumn{5}{|c|}{ Sources for seed } \\
\cline { 2 - 6 } & Own saved & Local market & kin & External agencies & Other specify \\
\hline Sorghum & & & & & \\
\hline \multirow{2}{*}{ Maize } & & & & & \\
\hline
\end{tabular}

Do you consider your sources for 2005-2011 as 'normal'? If not- explain

Normal sources for sorghum? Y N

Explain 
Normal sources for maize? Y N Explain

Part B. Formal and local seed

Please refer to part A. above.

1. Were the seed you sourced in \# 2 above local or formal? You can either write in the spaces provided under each type. - indicate by source and write $\mathrm{L}=$ local and $\mathrm{F}=$ formal (modern). List only the sources you actually used

\begin{tabular}{|l|l|l|l|l|l|}
\hline \multirow{2}{*}{ Crop } & \multicolumn{5}{|c|}{ Sources of seed } \\
\cline { 2 - 6 } & Own saved & Local market & Kin & External agencies & Other- specify \\
\hline Sorghum & & & & & \\
\hline Maize & & & & & \\
\hline
\end{tabular}

2. Which type of seed do you prefer?

\begin{tabular}{|l|l|}
\hline Crop & Type of seed variety preferred- Local or formal \\
\hline Sorghum & \\
\hline Maize & \\
\hline
\end{tabular}

Give reason for your answer.

\begin{tabular}{|l|}
\hline For sorghum: \\
\hline For maize: \\
\hline
\end{tabular}

3. How many local seed varieties of sorghum and maize do you know of? Please list them in the box below.

\begin{tabular}{|l|l|}
\hline Sorghum & Maize \\
\hline- & - \\
- & - \\
- & - \\
- & - \\
- & - \\
\hline
\end{tabular}

4. How many formal seed varieties of sorghum and maize do you know of? Please list them in the box below.

\begin{tabular}{|l|l|}
\hline Sorghum & Maize \\
\hline- & - \\
- & - \\
- & - \\
- & - \\
- & - \\
\hline
\end{tabular}

5. From numbers $3 \& 4$ above, how many varieties have you actually planted in the last three seasons (2009, 2010 \& 2011)? Also, specify if they are local or formal

\begin{tabular}{|l|l|l|}
\hline Sorghum variety name & Local & Formal \\
\hline- & - & - \\
- & - & - \\
- & - & - \\
- & - & - \\
- & - & - \\
\hline
\end{tabular}

\begin{tabular}{|l|l|l|}
\hline Maize variety name & Local & Formal \\
\hline- & - & - \\
- & - & - \\
- & - & - \\
- & - & - \\
- & - & - \\
- & - & - \\
\hline
\end{tabular}




\section{APPENDIX C:}

\section{Guided Questions for Focus Group Discussion}

1. There are many types of cereal crops grown by individual farmer over the periods before and during the war? Which one do you sense have been particularly important - and why

2. Where do you get seed for planting each season for each crop?

3. During stress times e.g. flood and drought before the war were you getting seed aid?

4. If not, then where were you getting seed for planting?

5. Immediately after the war, where and how have you been getting your planting material (seed)?

6. Are the seed you get from NGOs/Agencies familiar to you?

7. Which type of seed do you prefer? Local or formal? And why?

8. Comparing the yield of local and formal seed, which one yields better?

9. How many Kgs for instance do you normally get per feddan?

10. Which seed sources do you prefer: own saved, local market, kin, external agencies, other (specify). What are the advantages and disadvantages of using each source?

11. Do you know of any local sorghum and maize varieties that use to be grown in the past and currently not in circulation? If yes, what are the reasons they are no longer in circulation?

\section{Acknowledgement}

I would like to acknowledge the support from the following institutions and individuals who contributed both financially and in kind to make this work possible: the Norman Borlaug Institute of International AgricultureTexas AgriLife Research with funding from United States Agency for International Development (USAID) and Norwegian People's Aid (NPA).

I want to thank the following individuals: Dr. Louise Sperling who mentor me through this process; Prof. Patricia B. Mutch who guided on the style and formatting system of scholarly work and the University requirement; and my colleagues Mr. Moses Chuti; Mr. Abraham Mading; Ms. Atena Bol; Mr. Jacob Mamer; Mr. Manyang Chol who assisted me in data collection in one way or the other. I am grateful to all of you. 